\title{
Spinal poly-GA inclusions in a $C 90 r f 72$ mouse model trigger motor deficits and inflammation without neuron loss
}

\author{
Martin H. Schludi ${ }^{1,2} \cdot$ Lore Becker $^{3} \cdot$ Lillian Garrett $^{3,4} \cdot$ Tania F. Gendron $^{5}$ Qihui Zhou ${ }^{1,2} \cdot$ Franziska Schreiber $^{1}$.

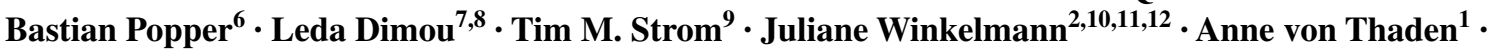 \\ Kristin Rentzsch $^{1} \cdot$ Stephanie May $^{1} \cdot$ Meike Michaelsen $^{1} \cdot$ Benjamin M. Schwenk $^{1} \cdot \operatorname{Jing}$ Tan $^{10} \cdot$ Benedikt Schoser $^{13}$. \\ Marianne Dieterich ${ }^{1,2,13}$ - Leonard Petrucelli ${ }^{5}$ Sabine M. Hölter ${ }^{3,4}$ - Wolfgang Wurst ${ }^{1,2,4,14}$ - Helmut Fuchs ${ }^{3}$. \\ Valerie Gailus-Durner $^{3}$ - Martin Hrabe de Angelis ${ }^{3,15,16}$ • Thomas Klopstock ${ }^{1,2,13}$ - Thomas Arzberger ${ }^{1,2,17,18}$. \\ Dieter Edbauer ${ }^{1,2,19}$ (i)
}

Received: 9 January 2017 / Revised: 4 April 2017 / Accepted: 4 April 2017 / Published online: 13 April 2017

(C) The Author(s) 2017. This article is an open access publication

\begin{abstract}
Translation of the expanded $(\text { ggggcc })_{n}$ repeat in C9orf72 patients with amyotrophic lateral sclerosis (ALS) and frontotemporal dementia (FTD) causes abundant polyGA inclusions. To elucidate their role in pathogenesis, we generated transgenic mice expressing codon-modified $(\mathrm{GA})_{149}$ conjugated with cyan fluorescent protein (CFP). Transgenic mice progressively developed poly-GA inclusions predominantly in motoneurons and interneurons of the spinal cord and brain stem and in deep cerebellar nuclei. Poly-GA co-aggregated with $\mathrm{p} 62, \operatorname{Rad} 23 \mathrm{~b}$ and the newly identified Mlf2, in both mouse and patient samples. Consistent with the expression pattern, 4-month-old
\end{abstract}

Electronic supplementary material The online version of this article (doi:10.1007/s00401-017-1711-0) contains supplementary material, which is available to authorized users.

Dieter Edbauer

dieter.edbauer@dzne.de

1 German Center for Neurodegenerative Diseases (DZNE) Munich, Feodor-Lynen-Straße 17, 81377 Munich, Germany

2 Munich Cluster for System Neurology (SyNergy), Feodor-Lynen-Straße 17, 81377 Munich, Germany

3 German Mouse Clinic, Institute of Experimental Genetics, German Research Center for Environmental Health, Helmholtz Zentrum München, Ingolstädter Landstrasse 1, 85764 Neuherberg, Germany

4 Institute of Developmental Genetics, German Research Center for Environmental Health, Helmholtz Zentrum München, Ingolstädter Landstrasse 1, 85764 Neuherberg, Germany

5 Department of Neuroscience, Mayo Clinic, 4500 San Pablo Road, Jacksonville, FL 32224, USA

6 Department of Anatomy and Cell Biology, Biomedical Center, Ludwig-Maximilians-University Munich, Großhaderner Str. 9, 82152 Planegg-Martinsried, Germany transgenic mice showed abnormal gait and progressive balance impairment, but showed normal hippocampusdependent learning and memory. Apart from microglia activation we detected phosphorylated TDP-43 but no neuronal loss. Thus, poly-GA triggers behavioral deficits through inflammation and protein sequestration that likely contribute to the prodromal symptoms and disease progression of C9orf72 patients.

Keywords ALS $\cdot$ FTLD $\cdot$ FTD $\cdot$ MND $\cdot$ C9orf72 . Neurodegeneration $\cdot$ Neurological disorder $\cdot$ Mouse model
7 Physiological Genomics, Biomedical Center, LudwigMaximilians-University Munich, Großhaderner Str. 9, 82152 Planegg-Martinsried, Germany

8 Molecular and Translational Neuroscience, Department of Neurology, University of Ulm, Albert-Einstein-Allee 11, 89081 Ulm, Germany

9 Institut für Humangenetik, Helmholtz Zentrum München, 85764 Munich, Germany

10 Institut für Neurogenomik, Helmholtz Zentrum München, 85764 Munich, Germany

11 Neurologische Klinik, Klinikum rechts der Isar, Technische Universität München, 81675 Munich, Germany

12 Institut für Humangenetik, Klinikum rechts der Isar, Technische Universität München, 81675 Munich, Germany

13 Department of Neurology, Friedrich-Baur-Institute, Klinikum der Ludwig-Maximilians-Universität München, Ziemssenstr. 1a, 80336 Munich, Germany 


\section{Introduction}

A $(\text { ggggcc })_{\mathrm{n}}$ hexanucleotide repeat expansion upstream of the coding region of C9orf72 is the most common genetic cause of amyotrophic lateral sclerosis (ALS) and frontotemporal dementia (FTD), with some patients showing symptoms of both diseases [7]. Patients usually carry several hundred or thousand ggggcc repeats compared to less than 30 in the general population. The repeat expansion inhibits C9orf72 expression, and sense and antisense transcripts may cause toxicity by sequestering RNA-binding proteins in nuclear foci $[6,28]$. Moreover, both sense and antisense repeat transcripts are translated from all reading frames into aggregating dipeptide repeat (DPR) proteins (poly-GA, -GP, -GR, -PA, and -PR) [1, 22, 23, 40]. The relative contribution of these putative pathomechanisms, and their link to the co-occurring TDP-43 pathology present in patients with $C 9$ orf $72 \mathrm{ALS} / \mathrm{FTD}$, are under intense debate.

Generating mouse models for $C 9$ orf 72 repeat expansion diseases has been surprisingly challenging [13]. Complete loss of $C 9$ orf 72 does not cause neurodegeneration, but does affect autophagy, particularly in the immune system, and leads to splenomegaly $[15,25]$. High level viral expression of a relatively short $\left(\mathrm{ggggcc}_{66}\right.$ repeat expansion leads to rapid neurodegeneration accompanied by DPR and TDP43 pathology [5]. In contrast, expressing lower levels of an expanded repeat in its endogenous context leads to variable results. Two BAC transgenic mouse lines showed the characteristic RNA foci and DPR inclusions of $C 9$ orf 72 ALS/FTD, but no neuron loss or behavioral symptoms [24, 26], while two similar mouse models additionally showed cognitive symptoms $[15,19]$. The more dramatic effects in the viral system may be due to higher expression levels and altered processing of exonic repeat expression [34]. Together, these models strongly support gain of function toxicity as the main cause of $C 9$ orf72 ALS/FTD, but

14 Chair of Developmental Genetics, Technische Universität München, Freising-Weihenstephan, Germany

15 Chair of Experimental Genetics, School of Life Science Weihenstephan, Technische Universität München, Alte Akademie 8, 85354 Freising, Germany

16 German Center for Diabetes Research (DZD), Ingolstädter Landstr. 1, 85764 Neuherberg, Germany

17 Center for Neuopathology and Prion Research, LudwigMaximilians-University Munich, Feodor-Lynen-Straße 23, 81377 Munich, Germany

18 Department of Psychiatry and Psychotherapy, LudwigMaximilians University Munich, Nußbaumstraße 7, 80336 Munich, Germany

19 Institute for Metabolic Biochemistry, Ludwig-MaximiliansUniversity Munich, Feodor-Lynen-Straße 17, 81337 Munich, Germany cannot differentiate the contribution of sense and antisense RNA transcripts and the five DPR species. Viral expression of the most abundant DPR species, poly-GA, in the mouse brain causes mild neurodegeneration and cognitive symptoms without TDP-43 pathology, but this system showed no expression in the spinal cord [37]. In patients, DPR proteins are less common in the spinal cord than in the brain, but they are also found in upper and lower motoneurons [31].

To elucidate the specific contribution of poly-GA to disease pathogenesis, we aimed to generate a transgenic mouse model with poly-GA expression levels comparable to C9orf72 ALS/FTD patients. We chose a Thyl-based expression vector for neuron-specific expression of polyGA [9]. Here, we report in-depth pathological and phenotypic analyses of these mice focusing on the motor system.

\section{Methods}

\section{Generation of Thy1 (GA) ${ }_{149}$-CFP mice $^{-C}$}

We inserted a multiple cloning site into the pUC18 based murine Thy 1.2 vector using synthetic oligonucleotides [9]. This allowed us to insert a cDNA encoding $(\mathrm{GA})_{149}, 31$ amino acids corresponding to the $3^{\prime}$ region of the poly-GA reading frame in patients [22] and cyan fluorescent protein (CFP) (sequence shown in Fig. S1a). Compared to the previous $(\mathrm{GA})_{149}$-GFP construct [21] only the fluorescent protein had been changed. Linearized vector was injected into C57BL/6-derived zygotes and transferred into pseudopregnant CD1 females (PolyGene). GA-CFP mice were kept in the C57BL/6N background. Mice were PCR genotyped using the following primers (tccaggagcgtaccatcttc; gtgctcaggtagtggttgtc). We confirmed maintenance of the full length transgene with PCR amplification (Expand Long Template PCR System, Roche, 11681842001; gatccaagcttgccaccatg; tctagctctgccactccaag) and sequencing.

The transgene integration site was determined by whole genome sequencing according to standard protocols using the TruSeq DNA PCR-Free Library Preparation Kit and an Illumina HiSeq 4000 with 150 bp paired-end reads resulting in about $58 \times$ coverage from two lanes. Sequences mates mapping to different chromosomes were analyzed using the Integrative Genomics Viewer (IGV) [33].

\section{Immunohistochemistry of mouse and patient tissue}

After killing, 1-, 3-, 6-, and 12-month-old mice were transcardially perfused with $1 \%$ sterile PBS and tissue was then formalin fixated for 2 days. Histological stainings were performed on 5-8 $\mu \mathrm{m}$ thick sections from paraffin-embedded tissue. For spinal cord tissue, an additional decalcification step with 5\% formic acid for 5 days was performed after formalin fixation. After 
deparaffinization in xylene and dehydration in graded ethanol, the paraffin sections were treated with citrate buffer $(\mathrm{pH} 6)$ for $20 \mathrm{~min}$ in the microwave. Mlf2 IHC staining was more prominent when the citrate retreatment was followed by $20 \mathrm{~min}$ incubation in $80 \%$ formic acid or 5-25 min incubation with $0.1 \mu \mathrm{g} /$ $\mu \mathrm{l}$ proteinase $\mathrm{K}$ in $10 \mathrm{mM}$ Tris/ $\mathrm{HCl} \mathrm{pH} 7.6$ at $37^{\circ} \mathrm{C}$. Afterwards the slides were incubated with primary antibody overnight at $4{ }^{\circ} \mathrm{C}$. For ChAT, an additional incubation with rabbit anti-goatIgG was performed the next day for $1 \mathrm{~h}$ at room temperature. The slides were detected by the DCS SuperVision 2 Kit (DCS innovative diagnostic-system, Hamburg, Germany) according to the manufacturer's instructions. Iba1 and GFAP immunohistochemistry was performed with the Ventana BenchMark XT automated staining system (Ventana) using the UltraView Universal DAB Detection Kit (Roche). For Nissl staining, the deparaffinized slides were incubated in $70 \%$ ethanol overnight. After $30 \mathrm{~min}$ in Cresyl violet and $1 \mathrm{~min}$ in 96\% ethanol the slides were processed in $100 \%$ ethanol with glacial acetic acid. Bright-field images were taken by CellD, Olympus BX50 Soft Imaging System (Olympus, Tokyo, Japan).

For immunofluorescence, after deparaffinization and citrate antigen retrieval, the slides were incubated with primary antibody overnight at $4{ }^{\circ} \mathrm{C}$ and the following day incubated for $1 \mathrm{~h}$ at room temperature with secondary Alexa Fluor labeled antibodies. For Mlf2 immunofluorescence staining, a $1 \mathrm{~min}$ treatment at $37{ }^{\circ} \mathrm{C}$ with $0.05 \mu \mathrm{g} /$ $\mu \mathrm{l}$ proteinase $\mathrm{K}$ in $10 \mathrm{mM}$ Tris/ $\mathrm{HCl} \mathrm{pH} 7.6$ was necessary before citrate antigen retrieval. After the nuclei were counterstained with DAPI, the slices were incubated for 1 min in $0.2 \%$ Sudan black B and mounted with Fluoromount Aqueous Mounting Medium (Sigma, F4680). Fluorescent images were taken using a LSM710 confocal laser scanning system (Carl Zeiss, Jena, Germany) with 20x or $40 \mathrm{x} / 63 \mathrm{x}$ oil immersion objectives.

\section{Antibodies}

$\alpha$-GFP (1:1000, Clonetech 632592), $\alpha$-GA clone 5F2 [20] (purified mouse monoclonal, WB unlabeled 1:50; IHC HRP labeled 5F2 1:2500, labeled by AbD Serotec HRPlabeling Kit LNK002P; biotinylated 5F2 7 ng/ $\mu$; MSDlabeled 5F2 $10 \mathrm{ng} / \mu \mathrm{l}$, labeled by Meso Scale MSD SulfoTag NHS-Ester R91AN-1), $\alpha$-GA-CT (C-terminal tail) clone 5C3 [22] (rat monoclonal, 1:50), $\alpha$-p62/SQSTM1 (IF 1:100, IHC 1:1000, MBL, PM045), $\alpha$-pTDP-43 (Ser409/ Ser410) clone 1D3 [20] (purified rat monoclonal, 1:50), $\alpha$-TDP-43 (1:1000, Cosmo Bio, TIP-TD-P09), $\alpha$-RanGAP1 (1:100, Abcam, ab92360), $\alpha$-nucleolin (1:1000, Abcam, ab50729), $\alpha$-CD68 (1:1000, Abcam, ab125212), $\alpha$-Iba1 (1:500, Wako, 091-19741), $\alpha$-GFAP (1:5000,Dako, Z0334), $\alpha$-NeuN (1:1000, Abcam, ab177487), $\alpha$-ChAT (IF 1:300, IHC 1:5000, Millipore, AB144P), $\alpha$-Calnexin (1:3000, Enzo Life Science, SPA-860F), $\alpha$-Calbindin
(1:300, Abcam, ab49899), $\alpha$-Calretinin (1:1000, Abcam, ab702) $\alpha$-Parvalbumin (1:750, Abcam, ab11427), $\alpha$-Mlf2 \#1 (1:1000, Sigma-Aldrich, HPA010811-100UL), $\alpha$-Mlf2 \#2 (1:1000, Santa Cruz, sc-166874), $\alpha$-Laminin (1:200, Abcam, ab11575), $\alpha$-goat-IgG (1:400, Dako, E0466), $\alpha$-mouse Alexa Fluor 488 (1:500, Thermo Fischer Scientific, A11029), $\alpha$-rabbit Alexa Fluor 488 (1:500, Thermo Fischer Scientific, A11034), $\alpha$-rat Alexa Fluor 488 (1:500, Thermo Fischer Scientific, A11006), $\alpha$-mouse Alexa Fluor 555 (1:500, Thermo Fischer Scientific, A21424), $\alpha$-rabbit Alexa Fluor 555 (1:500, Thermo Fischer Scientific, A21429), $\alpha$-rat Alexa Fluor 555 (1:500, Thermo Fischer Scientific, A21434), Streptavidin Alexa Fluor 488 (1:500, Thermo Fischer Scientific, S11223), nuclei were stained with DAPI (Roche Applied Science, Penzberg, Germany).

\section{Immunoassay analysis of poly-GA in tissue homogenates}

Mouse brainstem and spinal cord samples and C9orf72 patient motor cortex samples were sonicated in 500-700 $\mu \mathrm{l}$ of cold RIPA buffer $(137 \mathrm{mM} \mathrm{NaCl}, 20 \mathrm{mM}$ Tris $\mathrm{pH} 7.5$, $10 \%$ Glycin, $1 \%$ Triton X 100, 0.5\% Na-deoxycholate, $0.1 \%$ SDS, 2 mM EDTA, protease and phosphatase inhibitors). $100 \mu$ of this homogenized tissue stock solutions were diluted to $300 \mu \mathrm{l}$ with RIPA and centrifuged at $100,000 \times g$ for $30 \mathrm{~min}$ at $4{ }^{\circ} \mathrm{C}$. To avoid cross contamination, the RIPAinsoluble pellets were resuspended in $300 \mu \mathrm{l}$ RIPA, re-sonicated and re-centrifuged. Afterwards the RIPA-insoluble pellets were sonicated in U-RIPA (RIPA buffer containing $3.5 \mathrm{M}$ Urea) and the protein concentration determined by Bradford assay. Streptavidin Gold multi-array 96-well plates (Mesoscale, L15SA-1) were blocked for 30 min with block solution (1\% BSA, $0.05 \%$ Tween 20 in PBS) and incubated with biotinylated $\alpha$-GA clone $5 \mathrm{~F} 2$ overnight at $4{ }^{\circ} \mathrm{C}$. Equal amounts of protein of all samples were added in duplicate wells for $2 \mathrm{~h}$, followed by $2 \mathrm{~h}$ incubation with the secondary MSD-labeled $\alpha$-GA clone 5F2. Serial dilution of recombinant GST-GA 15 in blocking buffer was used to prepare a standard curve. The wells intensity of emitted light upon electrochemical stimulation was measured using the MSD Quickplex 520 and the background corrected by the average response obtained from blank wells. Sensitivity and specificity of the immunoassay were confirmed using purified 15-mer DPRs fused to GST (Fig. S3a, b).

\section{Phenotypic analysis of mice}

The study was conducted in accordance with European and national guidelines for the use of experimental animals, and the protocols were approved by the governmental committee (Regierungspräsidium Oberbayern, Germany). All experimenters were blind to the genotype. 
Barnes maze (Stoelting Europe, Ireland) assay to test spatial, hippocampus-dependent long-term memory in mice was performed on a circular surface (diameter $91 \mathrm{~cm}$ ) with 20 circular holes (diameter $5 \mathrm{~cm}$ ) around its circumference [3]. Under one hole was an "escape box" (diameter $4 \mathrm{~cm}$, depth $15 \mathrm{~cm}$ ). The table surface was brightly lit by overhead lightning ( $900 \mathrm{~lx})$. For each trial the mice had 3 min to find and hide in the "escape box". For the statistical analysis failed attempts were set to $3 \mathrm{~min}$.

In the balance beam test, the mice were placed on a wooden beam (round surface, length $58 \mathrm{~cm}$, diameter $8 \mathrm{~mm}$ ) and had $1 \mathrm{~min}$ to cross the beam. The test was finished either when the mice reached the end of the stick, they dropped down or the time ran out. For the statistical analysis failed attempts were set to $1 \mathrm{~min}$. The experimenters were blind to the genotype, and trials were either video documented or recorded by AnyMaze (Stoelting Europe). AnyMaze Software was used to track the mice and to analyze the data.

In the Rotarod test (Ugo Basile), we accelerated the spindle speed from 5 to $50 \mathrm{rpm}$ over $5 \mathrm{~min}$. The test finished either after $5 \mathrm{~min}$ or when the mouse dropped down. The average time of two trials with $1 \mathrm{~h}$ break in between was used.

Modified SHIRPA analysis and grip strength testing was performed as described [11].

The beam ladder consists of two Plexiglas screens connected with several metal beams of variable distance. The test is used to evaluate skilled walking of the mice. Mice traverse the ladder and foot slips of fore paws and hind paws are counted separately as well as the time to traverse the beam.

The open field test as an assessment of spontaneous exploratory and anxiety-related behavior in a novel environment was carried out as previously described [12, 14, 39]. It consisted of a transparent and infra-red light permeable acrylic test arena with a smooth floor (internal measurements: $45.5 \times 45.5 \times 39.5 \mathrm{~cm}$ ). Illumination levels were set at approximately $150 \mathrm{~lx}$ in the corners and $200 \mathrm{~lx}$ in the middle of the test arena. Each animal was placed individually into the middle of one side of the arena facing the wall and allowed to explore it freely for $20 \mathrm{~min}$. For data analysis, the arena was divided by the computer in two areas, the periphery defined as a corridor of $8 \mathrm{~cm}$ width along the walls and the remaining area representing the center of the arena (42\% of the total arena). Data were recorded and analyzed using the ActiMot system (TSE, Bad Homburg, Germany).

Acoustic startle and its prepulse inhibition were assessed using a startle apparatus setup (Med Associates Inc., VT, USA) including four identical sound-attenuating cubicles. The protocol is based on the Eumorphia protocol (http://www.empress.har.mrc.ac.uk), adapted to the specifications of our startle equipment, and constantly used in the primary screen of the GMC [30]. Background noise was $65 \mathrm{~dB}$, and startle pulses were bursts of white noise $(40 \mathrm{~ms})$. A session was initiated with a 5-min-acclimation period followed by five presentations of leader startle pulses $(110 \mathrm{~dB})$ that were excluded from statistical analysis. Trial types included prepulse alone trials at four different sound pressure levels $(67,69,73,81 \mathrm{~dB})$, and trials in which each prepulse preceded the startle pulse $(110 \mathrm{~dB})$ by a $50 \mathrm{~ms}$ inter-stimulus interval. Each trial type was presented ten times in random order, organized in ten blocks, each trial type occurring once per block. Inter-trial intervals varied from 20 to $30 \mathrm{~s}$.

\section{DNA constructs and lentivirus production}

cDNA of rat Mlf2 (NCBI Gene ID: 312709) containing an $\mathrm{N}$-terminal HA-tag was expressed from a lentiviral vector driven by human ubiquitin promoter (FUW2-HA). Previously described (GA) 175 -GFP cDNA expressed from a synthetic gene lacking repetitive $(\text { ggggcc })_{n}$ sequences with ATG start codon and EGFP was cloned in a lentiviral packing vector (FhSynW2) containing the human synapsin promoter [21]. Lentivirus was produced in HEK293FT cells (Life Technologies) as described previously [10].

\section{Cell culture, RNA isolation and immunoprecipitation}

Primary hippocampal neurons from embryonic day 19 rats were cultured and transduced with lentivirus as described previously [32]. Immunofluorescence staining was performed on 10 min PFA (4\% paraformaldehyde and 4\% sucrose) fixed primary neurons. The primary and secondary antibodies were diluted in GDB buffer $(0.1 \%$ gelatin, $0.3 \%$ Triton $\mathrm{X}-100,450 \mathrm{mM} \mathrm{NaCl}, 16 \mathrm{mM}$ sodium phosphate $\mathrm{pH}$ 7.4) and incubated over night at $4{ }^{\circ} \mathrm{C}$ or $1 \mathrm{~h}$ at room temperature. Confocal images were taken using a LSM710 confocal laser scanning system (Carl Zeiss, Jena, Germany) with $40 \times$ or $63 \times$ oil immersion objectives. RNA isolation and qPCR was performed as described previously [23] using the following primers (CD68 ttctgctgtggaaatgcaag and gagaaacatggccegaagt; Iba1 acagcaatgatgaggatctgc and ctctaggtgggtcttgggaac; GFAP tttctcggatctggaggttg and agatcgccacctacaggaaa; ACTB atggaggggaatacagccc and ttctttgcagctcettcgtt; GAPDH caacagcaactcccactcttc and ggtccagggtttcttactcctt).

\section{Patient material}

Tissue samples of patient autopsy cases were provided by the Neurobiobank Munich, Ludwig-Maximilians-University (LMU) Munich and collected according to the guidelines of the local ethics committee. 


\section{Statistics and analysis}

Statistical analysis was performed with GraphPad Prism software (version 7.01). For neuron and motoneuron count, images of the left and right anterior horns of the spinal cord were taken and all positively stained cells were manually counted. The count number represents the neurons/motoneurons averaged on one side. Experiments with two groups were analyzed by $t$ test (unpaired, two-sided, $t=$ size of the difference relative to the variation; $d f=$ degrees of freedom). Behavioral data was analyzed by two-way ANOVA with Bonferroni post hoc test ( $F=$ equality of variances).

\section{Phospho-TDP-43 immunoassays}

For phosphorylated TDP-43 measurements, sarkosyl-soluble and urea-soluble fractions of mouse spinal cord tissues were prepared as previously described [5]. In brief, 25-60 mg of tissue were subjected to a sequential extraction protocol using Tris-EDTA buffer (50 mM Tris pH 7.4, $50 \mathrm{mM} \mathrm{NaCl}$, 1 mM EDTA), high salt Triton X-100 buffer, Triton X-100 buffer $+30 \%$ sucrose, and sarkosyl buffer. Sarkosyl-insoluble material was further extracted in urea buffer. The protein concentrations of sarkosyl-soluble fractions were determined using a bicinchoninic acid assay (Thermo Scientific), whereas a Bradford assay was utilized to measure protein concentrations of urea-soluble fractions. Phosphorylated TDP-43 levels in both these fractions were evaluated using a sandwich immunoassay that utilizes MSD electrochemiluminescence detection technology [15]. A mouse monoclonal antibody that detects TDP-43 phosphorylated at serines 409 and 410 (Cosmo Bio, \#CAC-TIP-PTD-M01, 1:500) was used as the capture antibody. The detection antibody was a sulfo-tagged rabbit polyclonal C-terminal TDP-43 antibody

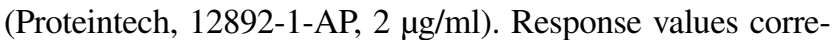
sponding to the intensity of emitted light upon electrochemical stimulation of the assay plate using the MSD QUICKPLEX SQ120 were acquired and background corrected using the average response from buffer only.

\section{Results}

\section{Thy1 (GA) ${ }_{149}$-CFP mice accumulate poly-GA inclusions in the spinal cord and brainstem}

We generated a Thyl-based vector to express (GA) ${ }_{149}$ using a synthetic sequence, which unlike the repeat expansion in patients has no extensive $(\text { ggggcc })_{n}$ stretches, fused with a C-terminal fluorescent CFP tag (Figs. 1a, S1a). Since the relevance of the $\mathrm{C}$-terminal tail of endogenous DPR products is unknown, we additionally included 31 amino acids translated from the endogenous locus in the poly-GA reading frame [22]. Using pronuclear injections into C57BL/6 mice, we generated a founder line (termed GA-CFP) with germline transmission and poly-GA expression. Transgenic mice were born at Mendelian frequency and did not differ in adult viability. Sequencing confirmed transmission of the full length open reading frame in all analyzed animals $(n=3$, data not shown) and genomic PCR from different tissues further confirmed the somatic stability of the synthetic repeat gene (Fig. $\mathrm{S} 1 \mathrm{~b})$. We identified the integration site using whole genome sequencing and validated our findings by PCR and Sanger sequencing (Fig. S2). Several transgene copies integrated on chromosome 14 about $330 \mathrm{~kb}$ downstream of the nearest transcript, the long non-coding RNA 4930474H20Rik, strongly suggesting that no endogenous genes are disrupted.

Using immunohistochemistry, we characterized polyGA protein expression in different brain regions in 4-6-month-old mice. Expression of the aggregated full length product was detected with antibodies targeting CFP, poly-GA or the C-terminal DPR tail (GA-CT) (Fig. S1c). While most of the poly-GA inclusions were cytoplasmic, a few inclusions were observed in the nucleus (Fig. S1d). In GA-CFP mice, poly-GA-inclusion pathology was restricted to neurons of brain stem, cerebellar nuclei and spinal cord. There were numerous poly-GA-immunopositive inclusions in large neurons of the brainstem, the lateral (dentate) and interposed cerebellar nuclei and (most abundantly) the anterior horn of the spinal cord, particularly in the cervical, thoracic and lumbar regions (Fig. 1b). Inclusion pathology was additionally observed in interneurons (Fig. S1e) in the laminae IV, V and VI of the posterior horn. No poly-GA inclusions were detected in the olfactory bulb, the molecular and granular layer of the cerebellum, the hippocampus or the neocortex, including the motor cortex (Fig. 1b).

Next, we analyzed the progression of poly-GA pathology in GA-CFP mice with age. Inclusions were visible by IHC in the spinal cord and brain stem at 1 month of age, and the number and size of inclusions increased with age (Fig. 1c). Consistent with these findings, levels of RIPA-insoluble poly-GA in brain stem and spinal cord lysates increased over time, as assessed using a poly-GA-specific immunoassay (Figs. 1d, e, S3a, S3b), whereas no signal was detected in non-transgenic littermates. No poly-GA was detectable in the RIPA-soluble fraction of the spinal cord and brainstem (Fig. S3c). Fair comparison of poly-GA levels in mice and patients is complicated by the different regional expression pattern in mice and patients and variable poly-GA levels in patients. However, we measured the expression of poly-GA in spinal cord of 4-6-month-old GA-CFP mice and motor cortex of $C 9$ orf72 ALS/FTD patients with abundant poly-GA pathology by immunoassay (Fig. S3d) and additionally counted the frequency of neuronal poly-GA inclusions in the most affected regions of GA-CFP mice 
a

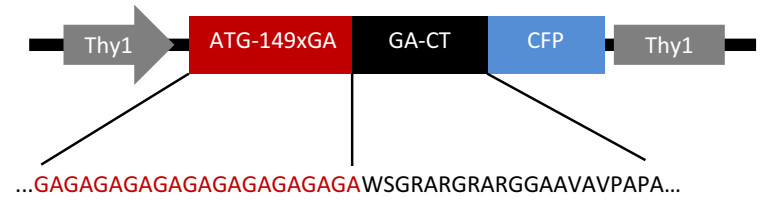

b

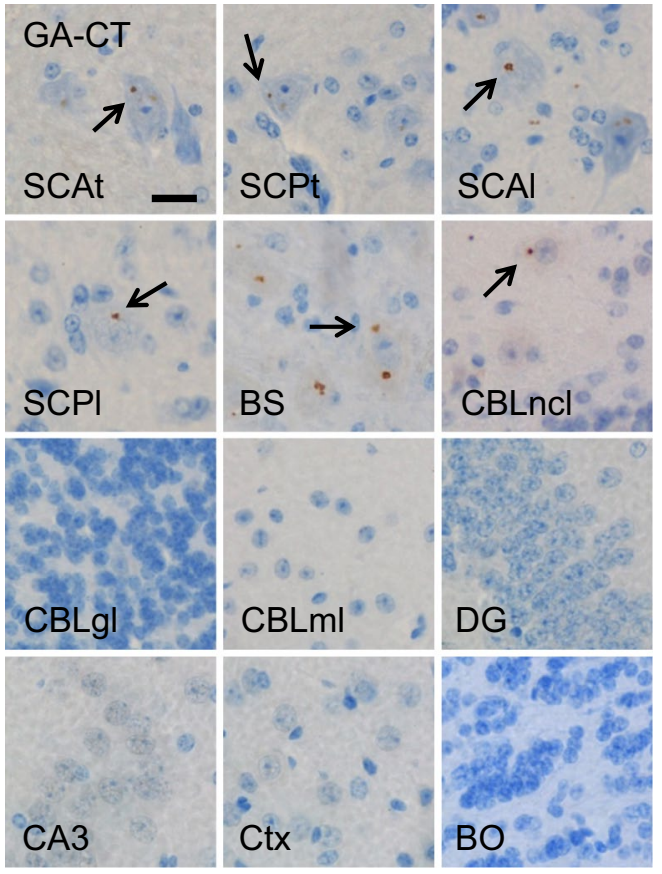

Fig. 1 Expression and distribution pattern of poly-GA aggregates in GA-CFP mice. a Schematic diagram of the construct containing the murine Thy 1 promoter driving expression of a synthetic gene encoding $(\mathrm{GA})_{149}$ with its endogenous C-terminal tail fused to CFP. (GA) ${ }_{149}$-CFP is replacing the endogenous coding region. b Distribution of GA aggregates show many inclusions in the spinal cord and brainstem and no aggregates in cortical regions, hippocampus or molecular and granular layer of the cerebellum. $B O$ olfactory bulb, $B S$ brainstem, $C A 3$ cornu ammonis fields $3, C B L g l$ cerebellar granular cell layer, $C B L m l$ cerebellar molecular cell layer, $C B L n c l$ lateral cerebellar nuclei, $D G$ dentate gyrus, $S C A l$ anterior horn of lumbar

and the neocortex of $C 9$ orf72 patients (Fig. S3e, f). Both assays show that poly-GA expression is not grossly exaggerated in GA-CFP mice. Thus, GA-CFP mice are a suitable model to address the pathomechanisms of poly-GA in the motor system.

\section{Poly-GA co-aggregates with p62, Rad23b and the chaperone-associated protein Mlf2}

To investigate potential downstream effects of poly-GA expression, we analyzed whether poly-GA co-aggregates

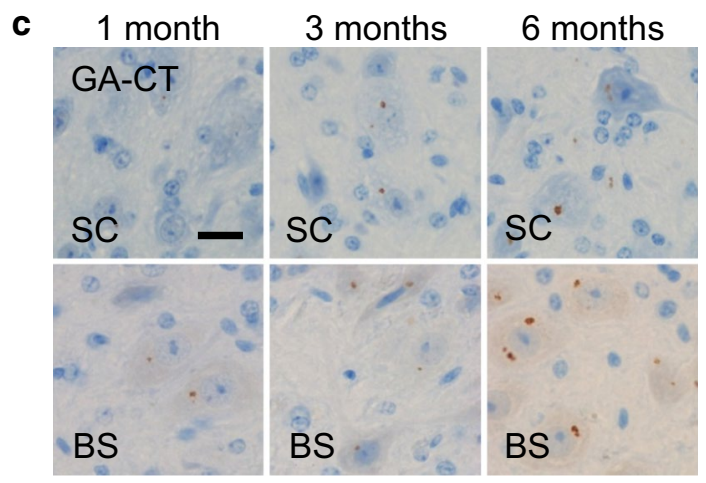

d

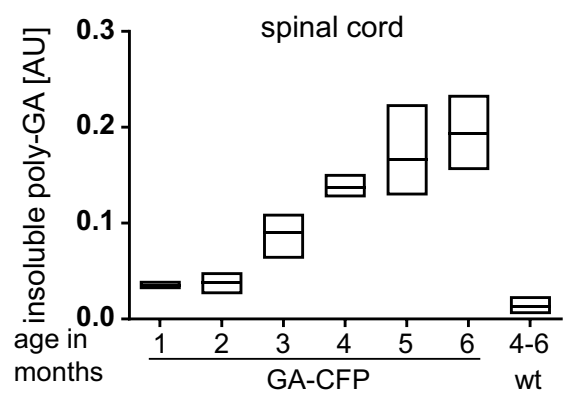

e

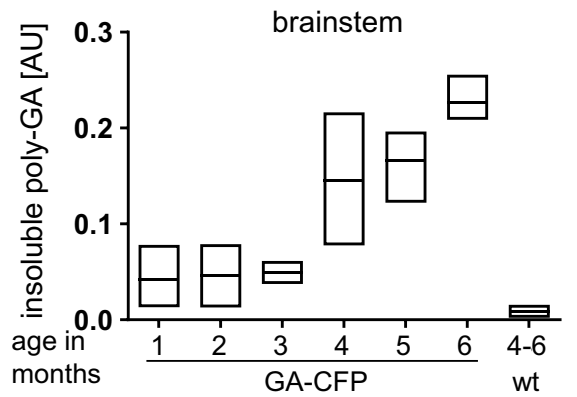

spinal cord, SCAt anterior horn of thoracic spinal cord, $S C P l$ posterior horn of lumbar spinal cord, $S C P t$ posterior horn of thoracic spinal corn. Scale bars represent $20 \mu \mathrm{m}$. c Increasing number and accumulation of aggregates in spinal cord (SC; upper row) and brainstem (BS; lower row) of 1-, 3- and 6-month-old GA-CFP mice detected by immunohistochemical staining using GA-CT antibody. Scale bar represents $20 \mu \mathrm{m}$. Quantitative immunoassay of RIPA-insoluble polyGA in the spinal cord (d) and brainstem (e) of 1-6-month-old GACFP mice ( $n=3$ mice per time-point; measured in duplicates) shows increasing amounts of poly-GA in a time dependent manner. $A U$ arbitrary unit, data are shown as mean, minimum and maximum

with other proteins. Similar to findings in C9orf72 ALS/ FTD patients [23], the vast majority of poly-GA inclusions co-localized with p62 (Fig. 2a, b, first row and Table S1). Rad23b, a known poly-GA-interacting protein involved in the ubiquitin proteasome pathway, also aggregated in GA-CFP mice (Fig. 2a, b, second row) similar to previous reports [21, 37]. In contrast to overexpression of polyGA in rat primary neurons [21], GA-CFP mice showed no sequestration of Unc119 (Fig. S4a) and no mislocalization or co-localization of RanGAP1 with poly-GA (Fig. S4b first row, and Table S1), which is consistent with our cell 

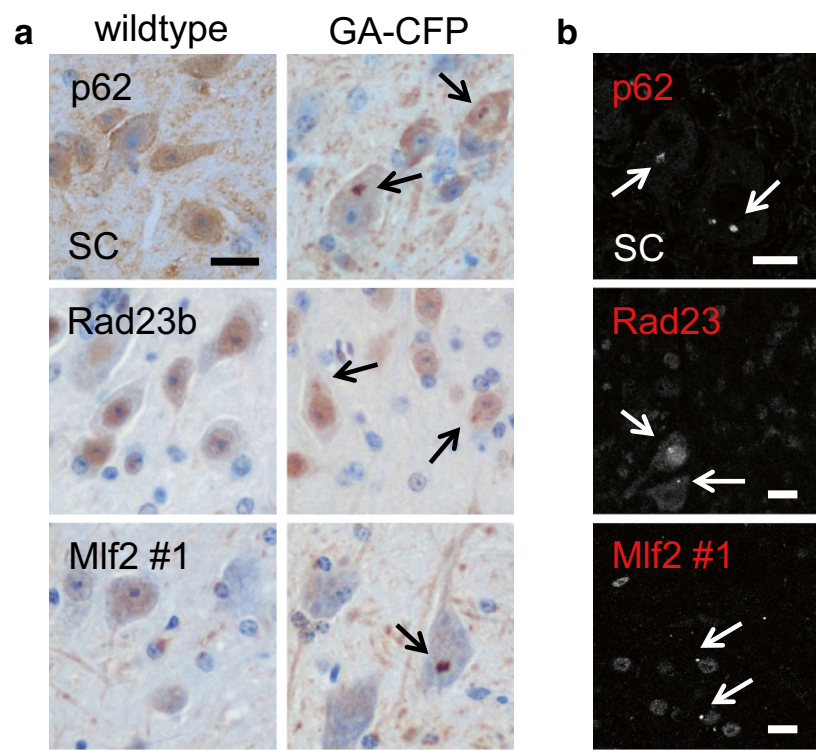

GA-CFP
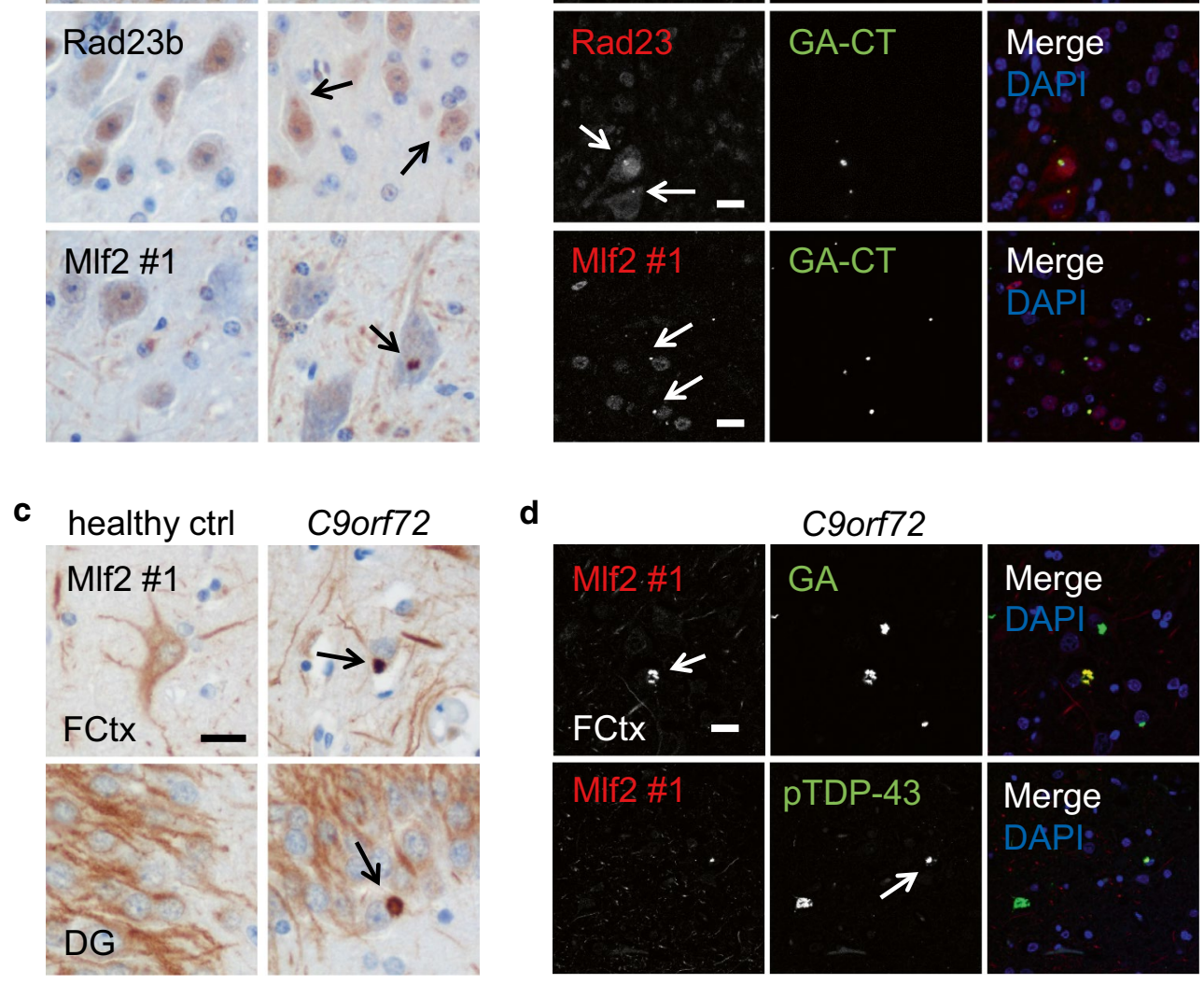

d

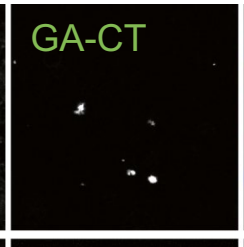

\section{Merge}

DAP
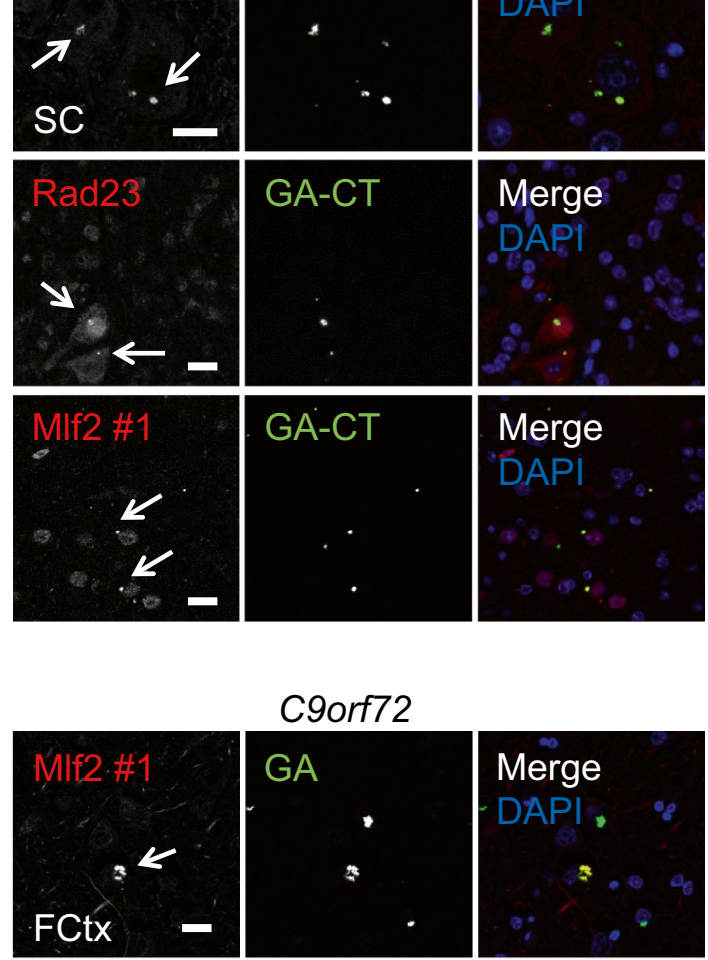

C9orf72
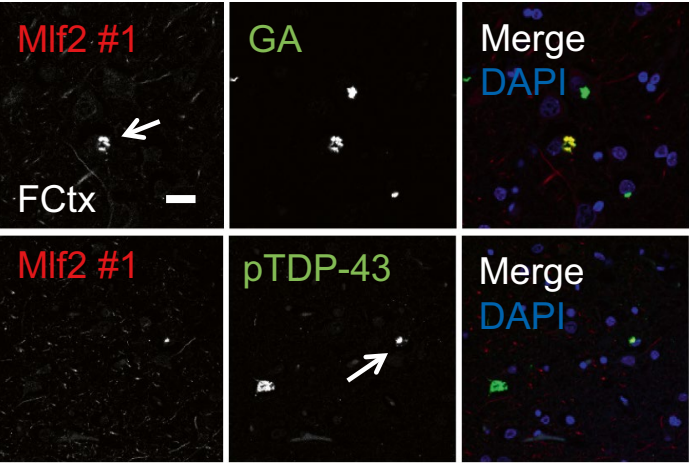

Fig. 2 GA-CFP mice develop p62, Rad23b and Mlf2 pathology similar to human $C 9$ orf 72 mutation carriers. a Immunohistochemistry shows p62, Rad23b and Mlf2 aggregates in the spinal cord (SC) of 6-month-old GA-CFP mice but not of wildtype mice. b Immunofluorescence stainings show $\mathrm{p} 62, \operatorname{Rad} 23 \mathrm{~b}$ and Mlf2 positive inclusions that co-localize with poly-GA in the spinal cord of 6-month-old GA-
CFP mice. c Immunohistochemistry detects specific Mlf2 aggregates in the frontal cortex (FCtx) and dentate gyrus (DG) of C9orf72 ALS/ FTLD patients. d Double immunofluorescence reveals colocalization of Mlf2 aggregates with poly-GA and phosphorylated TDP-43 inclusions in C9orf 72 patients. Scale bars represent $20 \mu \mathrm{m}$

poly-GA inclusions in primary neurons transduced with (GA) ${ }_{175}$-GFP (Fig. S4d). These data led us to examine Mlf2 aggregation in C9orf72 ALS/FTD patients. We detected Mlf2 pathology in the frontal cortex and hippocampus of C9orf72 ALS/FTD patients but not healthy controls using two independent Mlf2 antibodies (Figs. 2c, S4e). In addition, double immunofluorescence staining confirmed the co-aggregation of Mlf2 with poly-GA in $C 9$ orf 72 patients (Fig. 2d, first row). While in GA-CFP mice Mlf2 was coaggregating in $\sim 55 \%$ of the poly-GA inclusions, in $C 9$ orf 72 patients only $0.3-2.7 \%$ of the poly-GA aggregates showed Mlf2 sequestration, depending on the brain region (Table S2). However, we detected Mlf2 also occasionally in cytoplasmic phospho-TDP-43 inclusions in C9orf72 patients (Fig. 2d, second row). Thus, our GA-CFP mice recapitulate S4c). Moreover, endogenous Mlf2 was sequestered into 
the poly-GA component of pathology in C9orf72 ALS/ FTD patients, including the co-aggregation of poly-GA with p62, $\operatorname{Rad} 23 \mathrm{~b}$ and Mlf2.

\section{Poly-GA triggers mild TDP-43 phosphorylation but no overt neuron loss}

We next analyzed whether poly-GA expression drives neurodegeneration. Consistent with the expression pattern of the Thyl promoter, poly-GA was exclusively found in NeuN-positive neurons (Fig. 3a) and no expression was detectable in microglia or muscle fibers (Fig. S4f). However, Nissl staining and NeuN immunostaining revealed no overt neuron loss in the spinal cord (Fig. 3b, c). PolyGA was found in most choline acetyltransferase (ChAT) positive motoneurons in the anterior horn of the spinal cord (Fig. 3d), but ChAT immunostaining revealed no statistically significant loss of motoneurons at 6 months a

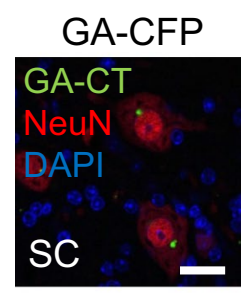

d

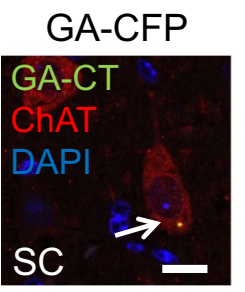

g

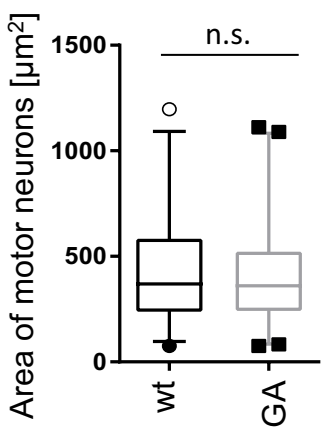

b

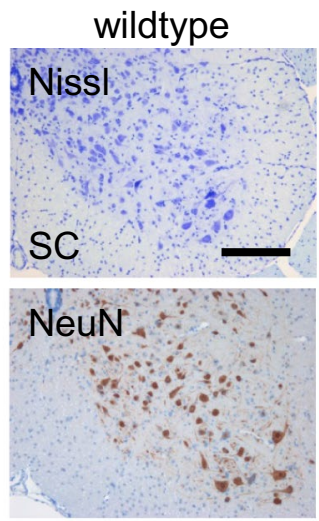

e

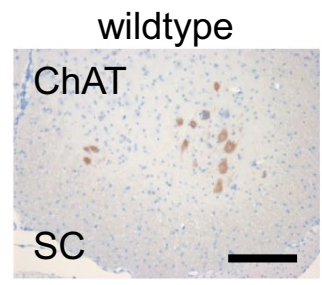

h

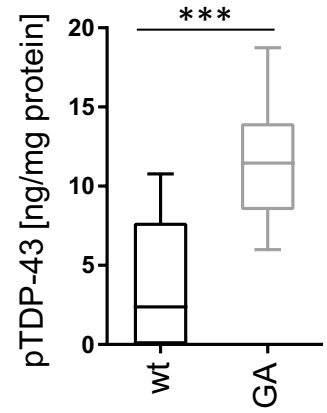

GA-CFP

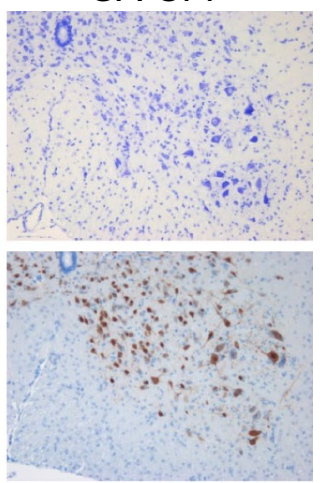

\section{GA-CFP}

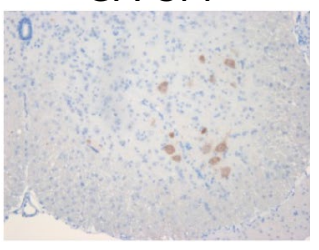

sarkosyl soluble

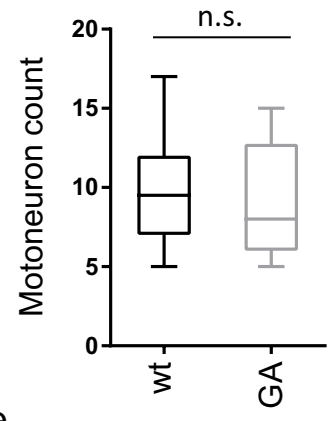

Fig. 3 GA-CFP mice show no evidence for neuronal loss but increased TDP-43 phosphorylation. a Double immunofluorescence of 6-month-old GA-CFP spinal cord tissue (SC) shows poly-GA inclusions exclusively in NeuN-positive cells. Scale bar represents $20 \mu \mathrm{m}$. b, c Nissl staining and NeuN immunohistochemistry of 6-month-old GA-CFP and wildtype spinal cords. Scale bar represents $100 \mu \mathrm{m}$. Quantitative analysis of NeuN-positive neurons shows no significant difference between wildtype and GA-CFP mice $\left(n_{\mathrm{GA}-\mathrm{CFP} / \mathrm{wt}}=3\right)$. d Immunostaining of poly-GA aggregates in choline acetyltransferase (ChAT)-positive motoneurons. Scale bar represents $20 \mu \mathrm{m}$. e-g Immunohistochemistry and quantitative analysis of ChAT-positive motoneurons of 6-month-old mice in the anterior horn of the spinal cord revealed no statistically significant differences in neuron count $\left(n_{\mathrm{GA}-\mathrm{CFP} / \mathrm{wt} \text { mice }}=4\right)$ and size $\left(n_{\mathrm{GA}-\mathrm{CFP} \text { motoneurons }}=228 ; n_{\mathrm{wt} \text { motoneu- }}\right.$ rons $=195)$. Neurons were counted as described in the "Statistics" section. Scale bar represents $100 \mu \mathrm{m}$. h Immunoassay for phosphorylated TDP-43 in sarkosyl (1\%)-soluble or urea (7M)-soluble spinal cord fractions from 6-month-old GA-CFP or wildtype (wt) mice. $n_{(\mathrm{wt})}=12 ; n_{(\mathrm{GA}-\mathrm{CFP})}=8$. Unpaired $t$ test (two-tailed; sarkosyl $t=0.3034, d f=18$; urea $t=4.172, d f=18$ ). Data are shown as box plot with whiskers at the 1st and 99th percentile. *** $p<0.001$, ns not significant 
(Fig. 3e-g). Furthermore, the size and shape of motoneurons in GA-CFP mice did not show signs of degeneration and were not discernible from the corresponding neurons in wildtype mice.

Next, we analyzed another neuropathological hallmark of ALS, namely TDP-43 phosphorylation, in aged GA-CFP mice. We quantified levels of phosphorylated TDP-43 (at serines 409 and 410) in the spinal cord of mice at 6 months of age by ELISA. Phosphorylated TDP-43 levels were approximately threefold higher in the urea-soluble (but sarkosyl-insoluble) fraction of GA-CFP mice compared to wildtype mice, but no difference was detected in the sarkosyl-soluble fraction (Fig. 3h). While mature TDP-43 inclusions and cytoplasmic TDP-43 mislocalization were not observed in GA-CFP mice, even at 12 months of age (Fig. S4g, h; Table S1), these data may nonetheless indicate that poly-GA contributes to the onset of TDP-43 pathology.

\section{Poly-GA induces microglia activation without astrogliosis}

Next, we analyzed the GA-CFP mice for signs of neuroinflammation. Immunohistochemistry for CD68 and Iba1 in 1- and 6-month-old mice revealed strong upregulation of these markers of phagocytic microglia in the spinal cord of 6-month-old GA-CFP mice (Fig. 4a, b) while little microglia activation was detectable at 1 month of age. Quantitative RT-PCR further confirmed enhanced mRNA expression of CD68 and Iba1 (Fig. 4c, d). In contrast, GFAP immunostaining and mRNA expression analysis revealed no signs of poly-GA-induced astrogliosis (Fig. 4e, f). Furthermore, in the neocortex of GACFP mice, a region lacking poly-GA pathology, no activation of CD68, Ibal or GFAP was detected (Fig. S5a). Thus, neuronal poly-GA expression induces regional microglia activation in the absence of overt neuron loss in GA-CFP mice.

\section{GA-CFP mice develop progressive motor deficits}

To analyze the functional consequences of poly-GA pathology and its downstream effects, we performed in depth phenotyping of mice at 3-4 months of age when poly-GA pathology starts building up. Open field testing revealed no signs of anxiety as GA-CFP and wildtype mice spent a similar time in the center of the arena, but the decreased rearing activity of GA-CFP mice may indicate decreased motor performance or alterations in the relevant brain circuits (Fig. 5a). The overall distance traveled was not significantly reduced in GA-CFP mice. However, when walking across a beam ladder with irregular step distance, male GA-CFP mice showed significantly more hind paw slips, without a difference in total traversing time (Fig. 5b). In the SHIRPA analysis, the majority of GA-CFP mice showed hind paw clenching
(84\% compared to $35 \%$ of controls; Fig. $5 \mathrm{c}$ ) and a broad, wagging gait ( $77 \%$ compared to $24 \%$ of controls). Grip strength of fore and hind limbs measured individually or combined was normal (data not shown). Decreased acoustic startle response and prepulse inhibition in GACFP mice suggest impaired sensorimotor gaiting and recruitment ability (Figs. S5b/c).

We repeated a subset of tests in 13-14-month-old mice. At this age, both male and female mice took significantly longer to cross the beam ladder and slipped more often with their hind paws (Fig. 5d). In the SHIRPA analysis, $87 \%$ of GA-CFP mice showed hind paw clenching compared to $8 \%$ of controls and abnormal gait (93\% compared to $38 \%$ of controls) (Fig. 5e). However, out of the sixty mice used for this study, only three control mice and one GA-CFP mouse had died unexpectedly until the age of 16 months.

We additionally used an independent, smaller cohort of mice from 2-6 months of age for a longitudinal study focusing on memory function and motor coordination. While GA-CFP and wildtype mice initially gained weight normally for the first 6 months (Fig. S5d), transgenic mice showed reduced body weight compared to wildtype littermates after 15 months (male wildtype $38.6 \mathrm{~g} \pm 3.1$, male GA-CFP $32.1 \mathrm{~g} \pm 1.7$, female wildtype $31.1 \mathrm{~g} \pm 4.0$, female GA-CFP $26.4 \mathrm{~g} \pm 2.3$; ANOVA genotype effect $p<0.001)$. Hippocampus-dependent spatial memory of all mice was tested weekly using the Barnes maze; at all time-points, GA-CFP mice performed like their wildtype littermates, indicating that their spatial memory was not impaired (Fig. S5e). Moreover, we used the accelerated rotarod as a test for overall motor performance. Within 6 months, no difference in the performance of motor planning and physical condition was observed between GACFP mice and wildtype littermates (Fig. S5f). To measure balance and coordination more directly, mice were made to walk across a balance beam every week. The beam walk revealed progressive deficits in male and female transgenic mice (Fig. 5f, g). GA-CFP mice and their wildtype littermates showed similar performance from week 8 to 17 , but from week 20 onward GA-CFP mice took a significantly longer time to cross the beam (Fig. 5f) or failed the test entirely by dropping down (Fig. $5 \mathrm{~g}$ ).

Taken together, GA-CFP mice develop progressive gait and balance impairments, while muscle strength and spatial memory are spared. These findings are consistent with the poly-GA pathology found exclusively in spinal cord, brainstem and cerebellum.

\section{Discussion}

We generated the first germline transgenic mouse model of pure DPR pathology without $(\operatorname{ggggcc})_{\mathrm{n}}$ repeat RNA 

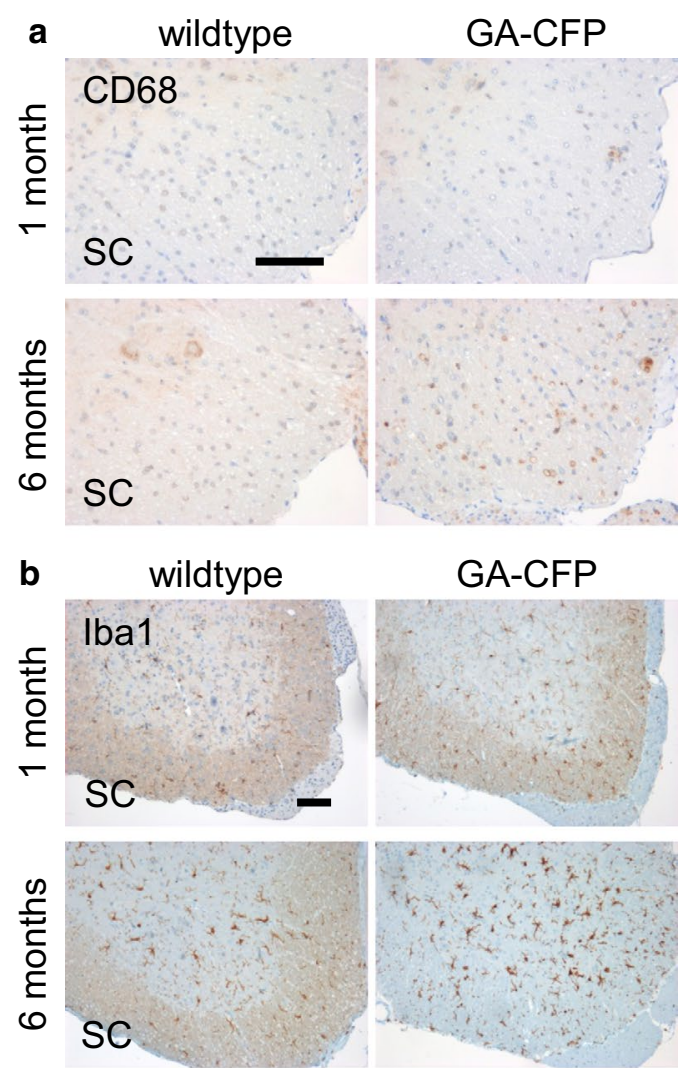

c $\quad$ CD68

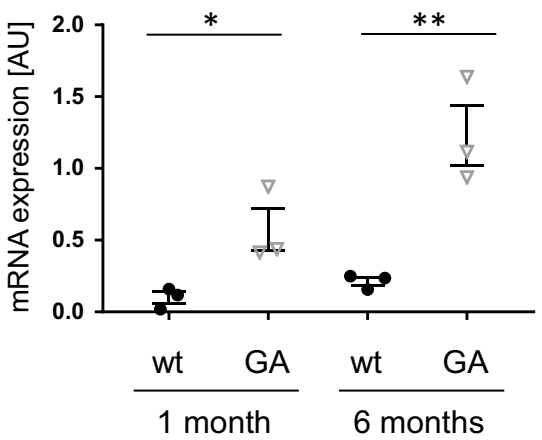

d

\section{lba1}
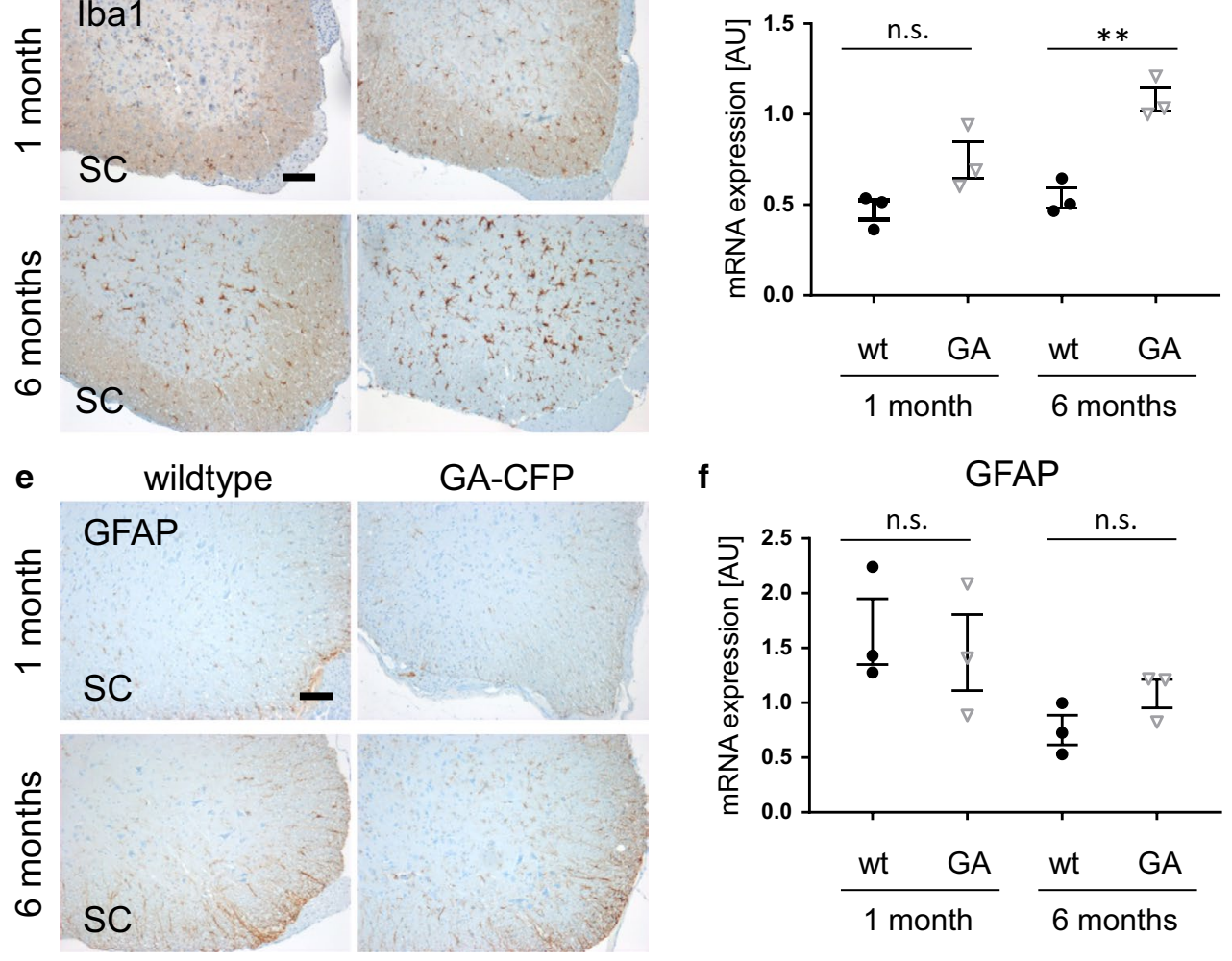

Fig. 4 Activation of phagocytic microglia in GA-CFP mice. a, b, e Immunohistochemistry of 1- and 6-month-old mice shows microglia activation detected by the markers CD68 and Iba1 in the spinal cord (SC) of 6-month-old GA-CFP mice compared to wildtype mice in the anterior horn of the spinal cord. No clear difference was observed for the astrocyte marker GFAP. Scale bars represent $100 \mu \mathrm{m}$. c, d, f Quantitative RT-PCR shows increased mRNA expression of CD68 and Iba1 but not GFAP in 6-month-old GA-CFP mice compared to

and analyzed the contribution of poly-GA to $C 9 \operatorname{orf} 72$ ALS/FTD pathophysiology. We show that chronic accumulation of poly-GA proteins in the spinal cord, brain stem and deep cerebellar nuclei in GA-CFP mice results in progressive gait and balance impairment. These deficits 1-month-old GA-CFP mice and controls. Expression was normalized to GAPDH and $\beta$-actin using the $\Delta \Delta C t$ method. $n_{(\mathrm{wt})}=3$; $n_{\text {(GA-CFP) }}=3$; Statistical analyses were performed by an unpaired $t$ test (two-tailed; CD68 ${ }_{1 \text {-month }} t=3.079, d f=4$ Iba1 $_{1 \text {-month }} t=2.385$, $d f=4 ; \mathrm{GFAP}_{1 \text {-month }} t=0.4147, d f=4 ; \mathrm{CD}_{6} 8_{6 \text {-months }} t=4.805$, $\left.d f=4 ; \mathrm{Iba1}_{6 \text {-months }} t=6.399, d f=4 ; \mathrm{GFAP}_{6 \text {-months }} t=1.771, d f=4\right)$ and data are shown as mean $\pm \mathrm{SEM} ;{ }^{*} p<0.05 ;{ }^{*} p<0.01$, $n s$ not significant

are associated with the sequestration of $\mathrm{p} 62, \operatorname{Rad} 23 \mathrm{~b}$ and the chaperone-associated protein Mlf2. Accompanying regional microglia activation and modest TDP-43 phosphorylation suggest that poly-GA inclusions impair neuronal function prior to neuron loss in $C 9$ orf72 ALS/FTD. 
a

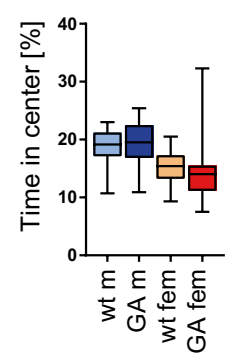

Open field (3 months)

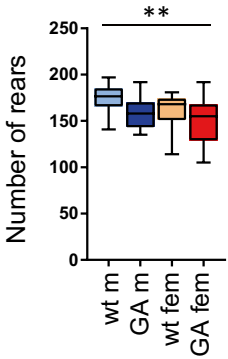

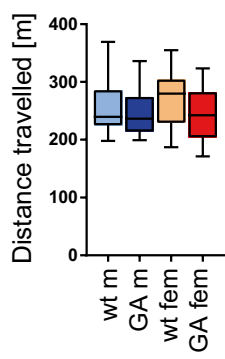

b

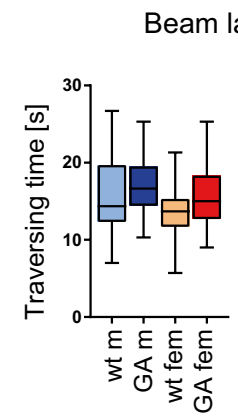

Beam ladder (3 months)

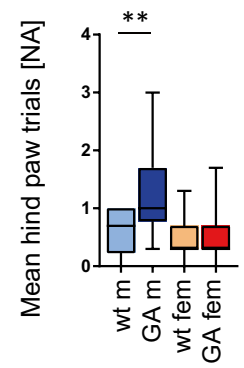

C

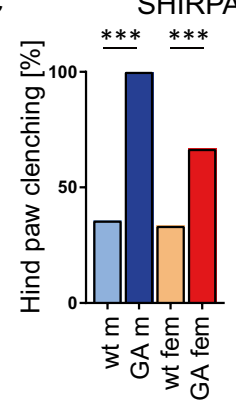

d

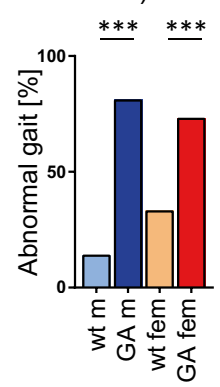

Beam ladder (14 months)

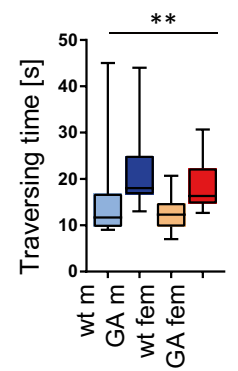

f

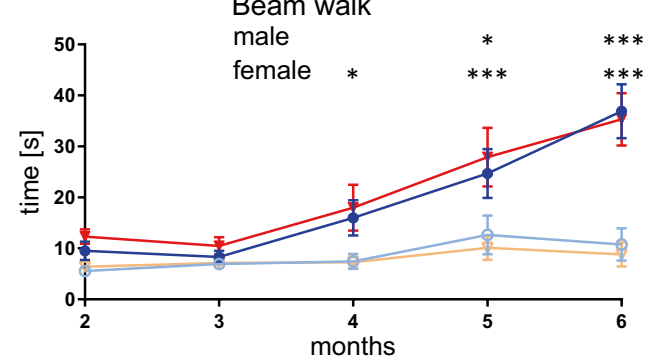

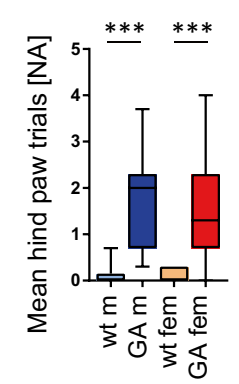

e

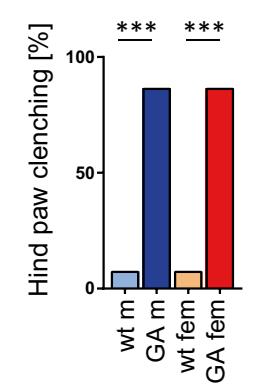

SHIRPA (14 months)

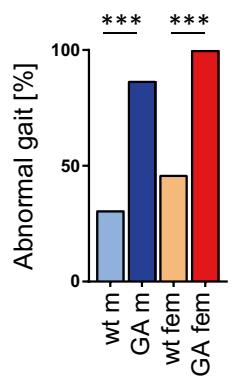

Beam walk - drop down rate

$$
\begin{aligned}
& - \text { wt male } \\
& - \text { GA male } \\
& - \text { wt female } \\
& - \text { GA female }
\end{aligned}
$$

g

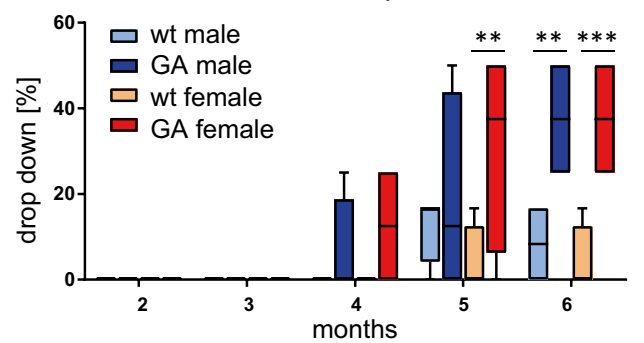

Fig. 5 GA-CFP mice are less active and develop balancing deficits. a-e Neurological and behavioral analysis of GA-CFP and wildtype (wt) littermates at 3-4 months (a-c) and 14 months of age (d, e). a Open field analysis at 3 months. Automated analysis of the time spent in the center, the rearing activity (total count) and the total distance traveled within 20 min for the different genotypes and genders. b Beam ladder with irregular step distance. Automated analysis of average time needed to cross the ladder and the number of hind paw slips at the age of 4 months. $c$ Gait analysis according to the SHIRPA protocol. Fraction of mice showing hindlimb clenching and abnormal gait is shown (at the age of 3.5 months). $n_{\text {(GA-CFP male) }}=16 ; n_{\text {(GA-CFP }}$ female) $=15 ; n_{\text {(wt male) }}=14 ; n_{\text {(wt female })}=15$ for all tests at 3 months of age. d, e Repetition of the beam ladder and SHIRPA analysis of GA-CFP and wildtype (wt) littermates at 14 months of age. $n_{\text {(GA- }}$ $\mathrm{CFP}_{\text {male })}=15 ; n_{(\mathrm{GA}-\mathrm{CFP} \text { female })}=15 ; n_{(\mathrm{wt} \text { male })}=13 ; n_{(\mathrm{wt} \text { female })}=13$. f, $g$ Longitudinal analysis using a balance beam. GA-CFP males

\section{GA-CFP mice model pure poly-GA pathology}

The Thyl-driven GA-CFP mice express poly-GA proteins at levels roughly similar to human C9orf72 ALS/FTD patients although with a different regional expression pattern. GA-CFP mice develop poly-GA pathology in motoneurons and other neurons of the spinal cord and brain stem and females take more time to cross the beam and fall more often than wildtype mice starting at 4 months. $n_{(\mathrm{GA}-\mathrm{CFP} \text { male })}=4 ; n_{\text {(GA-CFP }}$ female $)=4 ; n_{(\text {wt male })}=6 ; n_{(\text {wt female })}=6$. Statistical analysis of open field and beam ladder assay was performed by a two-way ANOVA between sex and genotype followed by Bonferroni post hoc test. Statistical analysis of the beam walk was performed by a two-way ANOVA between time and genotype for each sex followed by Bonferroni post hoc test. Asterisks for open field analysis and beam ladder traversing time depict significance of genotype effects [open field $F(1,56)=7.579$; beam ladder traversing time $F(1,52)=10.2]$. Asterisks for beam ladder hind paw trials, SHIRPA and beam walk depict significance of genotype and sex-dependent effects (Bonferroni). Statistical analysis of hind paw clenching and gait was performed by a Chi-square test. Data are shown as box plot with whiskers at the 1st and 99th percentille $(\mathbf{a}-\mathbf{e}, \mathbf{g})$ or as mean \pm SEM (f); $* p<0.05 ; * * p<0.01 ; * * * p<0.001$

and in deep cerebellar nuclei. In patients, poly-GA inclusions are found in the spinal cord, including motoneurons, but they are much more frequent in the neocortex, hippocampus, thalamus and cerebellum [20, 23, 31]. This has led to speculations that spinal cord motoneurons in patients may be particularly vulnerable to DPR protein expression. However, expression of poly-GA in GA-CFP mice does not 
cause a rapid loss of motoneurons. Our data indicate that poly-GA aggregates in neurons of the motor system disturb normal neuronal function in the absence of overt neuron loss, for example, by sequestration of cellular proteins.

We observed co-aggregation of poly-GA with p62 and $\operatorname{Rad} 23$ as reported previously [21, 23, 37]. For unknown reasons we did not detect sequestration of Unc119 into poly-GA inclusions in GA-CFP mice, which we had initially discovered in rat primary neurons and confirmed in C9orf72 patients [21, 31]. Furthermore, we discovered that the chaperone-associated protein Mlf2 co-aggregates with half of the poly-GA inclusions in the spinal cord of GACFP mice, but only in $0.3-2.7 \%$ of the poly-GA inclusions in the cortex of $C 9$ orf72 ALS/FTD patients. The differential co-aggregation of Mlf2 and Unc119 in GA-CFP mice and $C 9$ orf 72 cases highlights the importance of validating data from all model systems in patient tissue. The unexpected co-aggregation of Mlf2 and phospho-TDP-43 in C9orf 72 patients needs to be investigated further. While the drosophila homolog of Mlf2 has been shown to co-aggregate with poly-Q and modulate its toxicity in a Huntington's disease model $[16,18]$, preliminary experiments in rat primary neuron culture did not show clear effects of Mlf2 on poly-GA toxicity (data not shown).

Consistent with cellular models [21, 38], poly-GA expression by itself did not induce visible TDP-43 inclusions. However, we did notice increased levels of phosphorylated TDP-43 in the urea-soluble fraction, indicating that poly-GA may contribute to the onset of TDP-43 pathology. Similarly, in an AAV-based model with much higher GFP$(\mathrm{GA})_{50}$ expression, only very few TDP-43 aggregates were detected [37]. While C9orf72 patients show robust astrogliosis and microgliosis, the BAC transgenic and poly-GA expressing mice showed variable extent of astrocyte and microglia activation $[15,19,26,37]$. The strong activation of microglia in the spinal cord of our GA-CFP mice may be due to neuronal dysfunction alarming microglia, extracellular release of poly-GA aggregates [35] or low levels of neurodegeneration not detected by our quantitative analysis. In ALS patients, microglia activation correlates with disease progression, and C9orf72 carriers show higher microglia activation than non-carriers [4].

\section{Motor deficits in GA-CFP mice}

So far, no transgenic $C 9$ orf 72 model has robustly replicated the full complement of ALS and/or FTD phenotypes in animals. BAC transgenic mice with human-like C9orf72 expression levels show variable phenotypes and cannot differentiate between RNA and DPR toxicity [13]. Mice overexpressing poly-GA using AAV show signs of impaired nucleocytoplasmic transport and sequestration of Rad23b by poly-GA inclusions in the cortex [37]. Motor and balance deficits in these mice were attributed to the cerebellar poly-GA aggregation and neuron loss, because these mice rarely showed poly-GA inclusions in the spinal cord. In contrast, the motor system is directly affected in our transgenic GA-CFP mice. The motor phenotype of GA-CFP mice is consistent with the predominant expression of poly-GA in spinal cord and brain stem. Poly-GA inclusions in the deep cerebellar nuclei may further contribute to this phenotype. The impaired acoustic startle response and its prepulse inhibition, together with the distribution of poly-GA inclusions in the brainstem, suggest that poly-GA inhibits activity of this complex circuit involving the brain stem $[8,36]$. However, we cannot retrospectively exclude that early deafness may have affected these measurement in GA-CFP mice, because C57BL/6 mice commonly develop hearing loss at 3-6 months. By 14 months all female mice were deaf, while male GA-CFP mice were more severely affected than controls (data not shown).

The most prominent phenotype of GA-CFP mice, however, is their impaired balance and gait, which particularly affected the hind limbs. This is consistent with the widespread poly-GA pathology in the lumbar segments both in motoneurons and laminae IV, V and VI neurons implicated in proprioception. At 4 months of age, male mice slip more often with their hind paws on the beam ladder and show decreased rearing activity in the open field arena indicating deficits in motor control, which requires cortical input and proper function of the spinal cord circuits. Both male and female GA-CFP mice show enhanced hind limb clenching and an abnormal gait as well as progressive impairment on the balance beam starting at 3-4 months of age. Normal grip strength and endurance in the rotarod corroborates the absence of overt motoneuron loss and suggests poly-GA disturbs proper neuronal function and thus impairs coordination and motor control.

\section{Summary}

In patients, expression of poly-GA and the other DPR species correlates poorly with regional neuron loss $[20,31]$ and DPR pathology precedes overt ALS/FTD symptoms by many years $[2,27]$. Our findings suggest that polyGA-induced protein sequestration and regional microglia activation may be responsible for the prodromal cognitive deficits observed prior to complete ALS/FTD symptoms in C9orf72 mutation carriers [29]. Combined chronic DPR and RNA toxicity likely trigger the second disease stage with TDP-43 pathology and overt neuron loss [7]. Finally, GA-CFP mice are a good model to test poly-GA-based therapeutic approaches, because motor deficits appear early and homogeneously in all animals. 
Acknowledgements We thank M. K. Schmidt, B. Kraft, I. Pigur, I. Brandstetter and E. Graf for excellent technical assistance and A. Flately and R. Feederle for purified poly-GA antibodies. We thank G. Kleinberger, K. LaClair and B. Schmid for critical comments to the manuscript. We thank F. Bareyre for providing the Thy 1.2 empty vector.This work was supported by NOMIS foundation and the Hans und Ilse Breuer Foundation (D.E.), the Munich Cluster of Systems Neurology (SyNergy) (M.H.S., L.D., Q.Z., J.W., W.W., T.K. and D.E.), the European Community's Health Seventh Framework Programme under Grant Agreement 617198 [DPR-MODELS] (D.E.), the National Institutes of Health (NIH)/National Institute of Neurological Disorders and Stroke [P01NS084974 (L.P.); R01 NS093865-01 (L.P.)]; the ALS Association (T.F.G., L.P.), and the Muscular Dystrophy Association (T.F.G., L.P.) and by the German Federal Ministry of Education and Research (Infrafrontier Grant 01KX1012) (M.HdA.).

Author contributions MHS performed biochemical, pathological and neurological analysis. FS, BP, LD, AvT, JT, BS and MD contributed to the mouse phenotyping and study design. LB, LG, SMH, WW, VG-D, HF, MHdA designed, performed and supervised neurological and behavioral experiments at the German Mouse Clinic. TG and LP performed ELISA analysis of mouse tissue. BMS, QZ, KR, SM, MM and DE contributed to cell biological experiments and mouse generation. TMS, JW and DE analyzed the transgene integration site. TA supervised neuropathological analysis and provided human tissue. MHS, TK, TA and DE designed the project. DE and MHS wrote the manuscript with input from all coauthors.

Open Access This article is distributed under the terms of the Creative Commons Attribution 4.0 International License (http://creativecommons.org/licenses/by/4.0/), which permits unrestricted use, distribution, and reproduction in any medium, provided you give appropriate credit to the original author(s) and the source, provide a link to the Creative Commons license, and indicate if changes were made.

\section{References}

1. Ash PE, Bieniek KF, Gendron TF, Caulfield T, Lin WL, Dejesus-Hernandez M, van Blitterswijk MM, Jansen-West K, Paul JW 3rd, Rademakers R et al (2013) Unconventional translation of C9ORF72 GGGGCC expansion generates insoluble polypeptides specific to c9FTD/ALS. Neuron 77:639-646. doi:10.1016/j. neuron.2013.02.004

2. Baborie A, Griffiths TD, Jaros E, Perry R, McKeith IG, Burn DJ, Masuda-Suzukake M, Hasegawa M, Rollinson S, PickeringBrown $S$ et al (2014) Accumulation of dipeptide repeat proteins predates that of TDP-43 in frontotemporal lobar degeneration associated with hexanucleotide repeat expansions in C9ORF72 gene. Neuropathol Appl Neurobiol. doi:10.1111/nan.12178

3. Barnes CA (1979) Memory deficits associated with senescence: a neurophysiological and behavioral study in the rat. J Comp Physiol Psychol 93:74-104

4. Brettschneider J, Toledo JB, Van Deerlin VM, Elman L, McCluskey L, Lee VM, Trojanowski JQ (2012) Microglial activation correlates with disease progression and upper motor neuron clinical symptoms in amyotrophic lateral sclerosis. PLoS One 7:e39216. doi:10.1371/journal. pone.0039216

5. Chew J, Gendron TF, Prudencio M, Sasaguri H, Zhang YJ, Castanedes-Casey M, Lee CW, Jansen-West K, Kurti A, Murray $\mathrm{ME}$ et al (2015) Neurodegeneration. C9ORF72 repeat expansions in mice cause TDP-43 pathology, neuronal loss, and behavioral deficits. Science 348:1151-1154. doi:10.1126/ science.aaa9344

6. DeJesus-Hernandez M, Mackenzie IR, Boeve BF, Boxer AL, Baker M, Rutherford NJ, Nicholson AM, Finch NA, Flynn H, Adamson J et al (2011) Expanded GGGGCC hexanucleotide repeat in noncoding region of C9ORF72 causes chromosome 9p-linked FTD and ALS. Neuron 72:245-256. doi:10.1016/j. neuron.2011.09.011

7. Edbauer D, Haass C (2016) An amyloid-like cascade hypothesis for C9orf72 ALS/FTD. Curr Opin Neurobiol 36:99-106. doi:10.1016/j.conb.2015.10.009

8. Fendt M, Li L, Yeomans JS (2001) Brain stem circuits mediating prepulse inhibition of the startle reflex. Psychopharmacology 156:216-224

9. Feng G, Mellor RH, Bernstein M, Keller-Peck C, Nguyen QT, Wallace M, Nerbonne JM, Lichtman JW, Sanes JR (2000) Imaging neuronal subsets in transgenic mice expressing multiple spectral variants of GFP. Neuron 28:41-51

10. Fleck D, van Bebber F, Colombo A, Galante C, Schwenk BM, Rabe L, Hampel H, Novak B, Kremmer E, Tahirovic S et al (2013) Dual cleavage of neuregulin 1 type III by BACE1 and ADAM17 liberates its EGF-like domain and allows paracrine signaling. J Neurosci 33:7856-7869. doi:10.1523/ JNEUROSCI.3372-12.2013

11. Fuchs H, Gailus-Durner V, Adler T, Aguilar-Pimentel JA, Becker L, Calzada-Wack J, Da Silva-Buttkus P, Neff F, Gotz A, Hans W et al (2011) Mouse phenotyping. Methods 53:120 135. doi:10.1016/j.ymeth.2010.08.006

12. Garrett L, Lie DC, Hrabe de Angelis M, Wurst W, Holter SM (2012) Voluntary wheel running in mice increases the rate of neurogenesis without affecting anxiety-related behaviour in single tests. BMC neuroscience 13:61. doi:10.1186/1471-2202-13-61

13. Hayes LR, Rothstein JD (2016) C9ORF72-ALS/FTD: transgenic mice make a come-BAC. Neuron 90:427-431. doi:10.1016/j.neuron.2016.04.026

14. Holter SM, Stromberg M, Kovalenko M, Garrett L, Glasl L, Lopez E, Guide J, Gotz A, Hans W, Becker L et al (2013) A broad phenotypic screen identifies novel phenotypes driven by a single mutant allele in Huntington's disease CAG knock-in mice. PLoS One 8:e80923. doi:10.1371/journal.pone.0080923

15. Jiang J, Zhu Q, Gendron TF, Saberi S, McAlonis-Downes M, Seelman A, Stauffer JE, Jafar-Nejad P, Drenner K, Schulte D et al (2016) Gain of toxicity from ALS/FTD-linked repeat expansions in C9ORF72 is alleviated by antisense oligonucleotides targeting GGGGCC-containing RNAs. Neuron 90:535550. doi:10.1016/j.neuron.2016.04.006

16. Kazemi-Esfarjani P, Benzer S (2002) Suppression of polyglutamine toxicity by a Drosophila homolog of myeloid leukemia factor 1. Hum Mol Genet 11:2657-2672

17. Khosravi B, Hartmann H, May S, Mohl C, Ederle H, Michaelsen M, Schludi MH, Dormann D, Edbauer D (2016) Cytoplasmic poly-GA aggregates impair nuclear import of TDP-43 in C9orf72 ALS/FTLD. Hum Mol Genet. doi:10.1093/ hmg/ddw432

18. Kim WY, Fayazi Z, Bao X, Higgins D, Kazemi-Esfarjani P (2005) Evidence for sequestration of polyglutamine inclusions by Drosophila myeloid leukemia factor. Mol Cell Neurosci 29:536-544. doi:10.1016/j.mcn.2005.04.005

19. Liu Y, Pattamatta A, Zu T, Reid T, Bardhi O, Borchelt DR, Yachnis AT, Ranum LP (2016) C9orf72 BAC mouse model with motor deficits and neurodegenerative features of ALS/FTD. Neuron 90:521-534. doi:10.1016/j.neuron.2016.04.005

20. Mackenzie IR, Arzberger T, Kremmer E, Troost D, Lorenzl S, Mori K, Weng SM, Haass C, Kretzschmar HA, Edbauer D et al (2013) Dipeptide repeat protein pathology in C9ORF72 mutation 
cases: clinico-pathological correlations. Acta Neuropathol 126:859-879. doi:10.1007/s00401-013-1181-y

21. May S, Hornburg D, Schludi MH, Arzberger T, Rentzsch K, Schwenk BM, Grasser FA, Mori K, Kremmer E, Banzhaf-Strathmann J et al (2014) C9orf72 FTLD/ALS-associated Gly-Ala dipeptide repeat proteins cause neuronal toxicity and Unc119 sequestration. Acta Neuropathol 128:485-503. doi:10.1007/ s00401-014-1329-4

22. Mori K, Arzberger T, Grasser FA, Gijselinck I, May S, Rentzsch K, Weng SM, Schludi MH, van der Zee J, Cruts M et al (2013) Bidirectional transcripts of the expanded C9orf72 hexanucleotide repeat are translated into aggregating dipeptide repeat proteins. Acta Neuropathol 126:881-893. doi:10.1007/ s00401-013-1189-3

23. Mori K, Weng SM, Arzberger T, May S, Rentzsch K, Kremmer E, Schmid B, Kretzschmar HA, Cruts M, Van Broeckhoven $\mathrm{C}$ et al (2013) The C9orf72 GGGGCC repeat is translated into aggregating dipeptide-repeat proteins in FTLD/ALS. Science 339:1335-1338. doi:10.1126/science. 1232927

24. O'Rourke JG, Bogdanik L, Muhammad AK, Gendron TF, Kim KJ, Austin A, Cady J, Liu EY, Zarrow J, Grant S et al (2015) C9orf72 BAC transgenic mice display typical pathologic features of ALS/FTD. Neuron 88:892-901. doi:10.1016/j. neuron.2015.10.027

25. O'Rourke JG, Bogdanik L, Yanez A, Lall D, Wolf AJ, Muhammad AK, Ho R, Carmona S, Vit JP, Zarrow J et al (2016) C9orf72 is required for proper macrophage and microglial function in mice. Science 351:1324-1329. doi:10.1126/science.aaf1064

26. Peters OM, Cabrera GT, Tran H, Gendron TF, McKeon JE, Metterville J, Weiss A, Wightman N, Salameh J, Kim J et al (2015) Human C9ORF72 hexanucleotide expansion reproduces RNA foci and dipeptide repeat proteins but not neurodegeneration in BAC transgenic mice. Neuron 88:902-909. doi:10.1016/j. neuron.2015.11.018

27. Proudfoot M, Gutowski NJ, Edbauer D, Hilton DA, Stephens M, Rankin J, Mackenzie IR (2014) Early dipeptide repeat pathology in a frontotemporal dementia kindred with C9ORF72 mutation and intellectual disability. Acta Neuropathol 127:451-458. doi:10.1007/s00401-014-1245-7

28. Renton AE, Majounie E, Waite A, Simon-Sanchez J, Rollinson S, Gibbs JR, Schymick JC, Laaksovirta H, van Swieten JC, Myllykangas L et al (2011) A hexanucleotide repeat expansion in C9ORF72 is the cause of chromosome 9p21-linked ALS-FTD. Neuron 72:257-268. doi:10.1016/j.neuron.2011.09.010

29. Rohrer JD, Nicholas JM, Cash DM, van Swieten J, Dopper E, Jiskoot L, van Minkelen R, Rombouts SA, Cardoso MJ, Clegg $S$ et al (2015) Presymptomatic cognitive and neuroanatomical changes in genetic frontotemporal dementia in the Genetic Frontotemporal dementia Initiative (GENFI) study: a crosssectional analysis. Lancet Neurol 14:253-262. doi:10.1016/ S1474-4422(14)70324-2
30. Saarikangas J, Kourdougli N, Senju Y, Chazal G, Segerstrale M, Minkeviciene R, Kuurne J, Mattila PK, Garrett L, Holter SM et al (2015) MIM-induced membrane bending promotes dendritic spine initiation. Dev Cell 33:644-659. doi:10.1016/j. devcel.2015.04.014

31. Schludi MH, May S, Grasser FA, Rentzsch K, Kremmer E, Kupper C, T. K, Degeneration GCfFL, Alliance BBB, Arzberger T et al (2015) Distribution of dipeptide repeat proteins in cellular models and C9orf72 mutation cases suggests link to transcriptional silencing. Acta Neuropathol 130:537-555. doi:10.1007/ s00401-015-1450-z

32. Schwenk BM, Lang CM, Hogl S, Tahirovic S, Orozco D, Rentzsch K, Lichtenthaler SF, Hoogenraad CC, Capell A, Haass C et al (2014) The FTLD risk factor TMEM106B and MAP6 control dendritic trafficking of lysosomes. EMBO J 33:450-467. doi:10.1002/embj.201385857

33. Thorvaldsdottir H, Robinson JT, Mesirov JP (2013) Integrative Genomics Viewer (IGV): high-performance genomics data visualization and exploration. Brief Bioinform 14:178-192. doi:10.1093/bib/bbs017

34. Tran H, Almeida S, Moore J, Gendron TF, Chalasani U, Lu Y, Du $X$, Nickerson JA, Petrucelli L, Weng Z et al (2015) Differential toxicity of nuclear RNA Foci versus dipeptide repeat proteins in a Drosophila model of C9ORF72 FTD/ALS. Neuron 87:12071214. doi:10.1016/j.neuron.2015.09.015

35. Westergard T, Jensen BK, Wen X, Cai J, Kropf E, Iacovitti L, Pasinelli P, Trotti D (2016) Cell-to-cell transmission of dipeptide repeat proteins linked to C9orf72-ALS/FTD. Cell Rep 17:645652. doi:10.1016/j.celrep.2016.09.032

36. Yeomans JS, Frankland PW (1995) The acoustic startle reflex: neurons and connections. Brain Res Brain Res Rev 21:301-314

37. Zhang YJ, Gendron TF, Grima JC, Sasaguri H, Jansen-West K, $\mathrm{Xu}$ YF, Katzman RB, Gass J, Murray ME, Shinohara M et al (2016) C9ORF72 poly(GA) aggregates sequester and impair HR23 and nucleocytoplasmic transport proteins. Nat Neurosci 19:668-677. doi:10.1038/nn.4272

38. Zhang YJ, Jansen-West K, Xu YF, Gendron TF, Bieniek KF, Lin WL, Sasaguri H, Caulfield T, Hubbard J, Daughrity L et al (2014) Aggregation-prone c9FTD/ALS poly(GA) RAN-translated proteins cause neurotoxicity by inducing ER stress. Acta Neuropathol 128:505-524. doi:10.1007/s00401-014-1336-5

39. Zimprich A, Garrett L, Deussing JM, Wotjak CT, Fuchs H, Gailus-Durner V, de Angelis MH, Wurst W, Holter SM (2014) A robust and reliable non-invasive test for stress responsivity in mice. Front Behav Neurosci 8:125. doi:10.3389/ fnbeh.2014.00125

40. Zu T, Liu Y, Banez-Coronel M, Reid T, Pletnikova O, Lewis J, Miller TM, Harms MB, Falchook AE, Subramony SH et al (2013) RAN proteins and RNA foci from antisense transcripts in C9ORF72 ALS and frontotemporal dementia. Proc Natl Acad Sci USA 110:E4968-E4977. doi:10.1073/pnas.1315438110 